\title{
The Integrated Rock Tunnel Data Logging and Decision-aid System
}

\author{
Sou-Sen Leu and Chung-Chin Dai \\ Department of Construction Engineering \\ National Taiwan Institute of Technology \\ Taipei, Taiwan, R.O.C.
}

\begin{abstract}
The construction process of a NATM tunnel consists of geological data logging and rock mass classification, monitoring of the changes of rock strain and stress, as well as blasting and excavation. Nevertheless, the disadvantages of traditional manual recording of tunnel-related information are: 1) it is difficult to record data in the poor jobsite environment, 2) the storage of these data is very poor, 3) it is not easy to analyze these data to provide more in-depth information to the construction process. This paper adopts decision support system (DSS) to establish "The Integrated Rock Tunnel Data Logging and Decision-aid System (RTLD)." The system consists of database subsystem, decision module subsystem and dialog subsystem. The system has a convenient decision-aid interface and an integrated data structure that encompasses all the tunnel-related information. The functions of the system include geological data logs (through semi-automatic image processing), 3D geology prediction, rock mass classification, rock monitoring data recording and graphical display, data recording and display of construction process and resources, and data correlation analysis.
\end{abstract}

\section{INTRODUCTION}

A NATM tunnel construction process consists of geological data logging and rock mass classification, monitoring of the changes of rock strain and stress, as well as blasting and excavation. These tasks are performed partially in series and partially in parallel. Nevertheless, the rock mass classification and monitoring are key to the success of the tunnel construction. Traditionally, when conducting the rock mass classification, engineers need to manually record rock conditions (such as orientation, discontinuities, rock types, and so on ) into geological sheets and then fill up mass rating tables to calculate the total score. Based upon the score, an appropriate construction method is recommended. The monitoring procedures are almost the same and the results are displayed on the trend charts. There are three disadvantages in the traditional way. At first, it is difficult and not efficient 
to perform All of the tasks in the poor jobsite environment. Secondly, the storage of these data will be very poor. Finally, it is not easy to analyze the correlation among these data, and which may provide more in-depth information to the construction process.

In order to improve the situation, this paper combines the concepts of decision support system (DSS) and image processing to establish a real-time tunnel decision support system, named "The Integrated Rock Tunnel Data Logging and Decision-aid System (RTLD)." The concept of "Decision support System" is adopted to establish the whole architecture, which consist of database subsystem, decision module subsystem and dialog subsystem. This system has a convenient decision-aid interface and an integrated data structure that encompasses all the tunnel-related information. The object-oriented data model (OODM) is first used to organize the tunnel-related information, such as rock condition and rock monitoring data. The experts' experiences and feedback information formulate the decision-aid module subsystem. Finally, the Microsoft Visual Basic ${ }^{\mathrm{TM}}$ is adopted to build up the multimedia dialog subsystem. Furthermore, geological data are recorded through an image processing system, which includes a digital camera and an image processing software, the U-lead ImagePals ${ }^{\mathrm{TM}}$. The functions of the system include geological data logs through semi-automatic image processing, 3D geology prediction, rock mass rating, rock monitoring data recording and graphical display, construction process data collection and analysis, construction method recommendation and warning system, as well as correlation analysis among rock condition, monitoring and construction data.

\section{DEVELOPMENT PROCESS OF THE RTLD}

The proposed system is based on a database design methodology called the three-schema architecture [Elmasri 89] and the decision support system [Sprague 89]. The three-schema architecture defines three abstraction levels: the external (view) level, the conceptual level, and the internal (physical) level. The major objective of the external level is to define the functions and expected goals of the system, based on the collection and analysis of users' requirements. The major function of the conceptual level is using a conceptual data model to describe the global structure of the system, regardless of the details of data structures and functions. The major objective of the internal function is to develop the physical system using a commercial database system. The paper also employs the concept of the "Decision support system" to enhance the functions of the system, based upon expertise and feedback information to formulate the decision module subsystem.

\section{ANALYSIS OF USERS' REQUIREMENTS}

During the tunnel construction cycle, the information is generated from activities of geological survey, rock mass classification, monitoring, and construction. These pieces of information are voluminous, highly interrelated and heterogeneous. Nevertheless, the traditional management of the information is not efficient, due to lack of complete data 
organization. In order to improve these situations, a computer system, the RTLD, is generated. Moreover, the computer system needs to provide sufficient decision aids to assist engineers in site judgments. The functions of the system are summarized in Table 1.

Table 1 The Summary Table of System Functions

\begin{tabular}{|c|l|}
\hline System Functions & \multicolumn{1}{|c|}{ Description } \\
\hline Geological Data Logs & $\begin{array}{l}\text { recording orientation (strike and dip angles) of } \\
\text { rock joints, faults and bedding planes, as well as } \\
\text { rock types }\end{array}$ \\
\hline $\begin{array}{c}\text { Multiple Data Entry of } \\
\text { Rock Mass Classification }\end{array}$ & $\begin{array}{l}\text { multiple data entries and cross references of each } \\
\text { classification parameter of RMR or Q methods }\end{array}$ \\
\hline $\begin{array}{c}\text { Excavation face preview } \\
\text { Monitoring Data Input \& } \\
\text { Analysis }\end{array}$ & $\begin{array}{l}\text { excavation face, based on information of existing } \\
\text { consecutive joints, faults and bedding planes } \\
\text { recording of monitoring data and trend display, } \\
\text { including convergence devices, settlement pins, } \\
\text { measuring bolts, borehole extensometers, etc.) }\end{array}$ \\
\hline $\begin{array}{c}\text { Construction Data Input \& } \\
\text { Analysis }\end{array}$ & $\begin{array}{l}\text { recording and statistical analysis of construction } \\
\text { data (progress and resource utilization) }\end{array}$ \\
\hline $\begin{array}{c}\text { Data Correlation Analysis } \\
\text { correlation analysis among rock condition, } \\
\text { monitoring, and construction data }\end{array}$ \\
\hline Disaster Data Logs & recording of tunnel disasters and treatments \\
\hline $\begin{array}{c}\text { Construction Method \& } \\
\text { Warning System }\end{array}$ & $\begin{array}{l}\text { production of construction methods and warning } \\
\text { status, based upon expertise and in situ data }\end{array}$ \\
\hline
\end{tabular}

\section{CONCEPTUAL ANALYSIS OF THE RTLD}

The goal of the conceptual phase is to translate the requirements of the external level into a formal representation called a conceptual schema. This involves a complete description of the data structure, meaning(semantics), interrelationships, and constraints. A high-level data model, often called a conceptual data model, is used in this phase. Conceptual models, such as the network data model and the relational data model, are based on flat data structures which are well suited for homogeneous data types. These, however, do not have sufficient semantic expressive functions to describe the relationships of entities. More appropriate is the objectoriented data model. The systematic approach of the object-oriented data model, the Object Modeling Techniques (OMT), is used to model the system [Booch 91]. The OMT combines three views of modeling systems. The object data model represents the static data structure. The dynamic model represents the temporal and behavioral aspects of the system. The function model shows the transformations of the system. 


\section{OBJECT-ORIENTED DATA MODEL}

\section{- object definition}

Central to the object-oriented Data Model (OODM) are the definitions of objects and relationships between objects. The two principal OODM objects are classes and instances. A class plays a major role in the object data model: as type definition. The class is used to define data structures of instance objects of a certain type. For example, the class rock mass classification defines instance variables, such as RQD, groundwater condition, etc., that are pertaining to instance objects of the class rock mass classification.

\section{- object relationships}

The object components described above are analogous to the data structures of conventional data model. Furthermore, three basic object relationships in the OODM are provided to enhance its expressive power: generalization, aggregation, and classification.

- Generalization - generalizations refers to an abstraction in which a set of similar classes is to form a higher level class. Thus, differences among similar objects are ignored to form a high-level class in which the similarities are emphasized. The significant meaning in generalization is to support data abstraction hierarchies which enhance the data organization of the RTLD.

- Aggregation - aggregation is an abstraction for building composite objects from their component objects. For example, the parameter rock faults in RMR contain spacing, condition, and orientation of discontinuities.

- Classification - classification is a form of abstraction in which a collection of instances is considered a class. Unlike generalization, classification focuses on the relationships between classes and their related instances.

\section{DYNAMIC MODEL AND FUNCTION MODEL}

As mentioned above, the dynamic model is to examine changes to the objects and their relationships over time. In the OMT, two major components of the dynamic model are events and states. Moreover, the function model describes computation results within a system, without specifying how or when they are computed. Based upon the survey of the OMT, the whole structure of the RTLD is shown in Figure 1. 


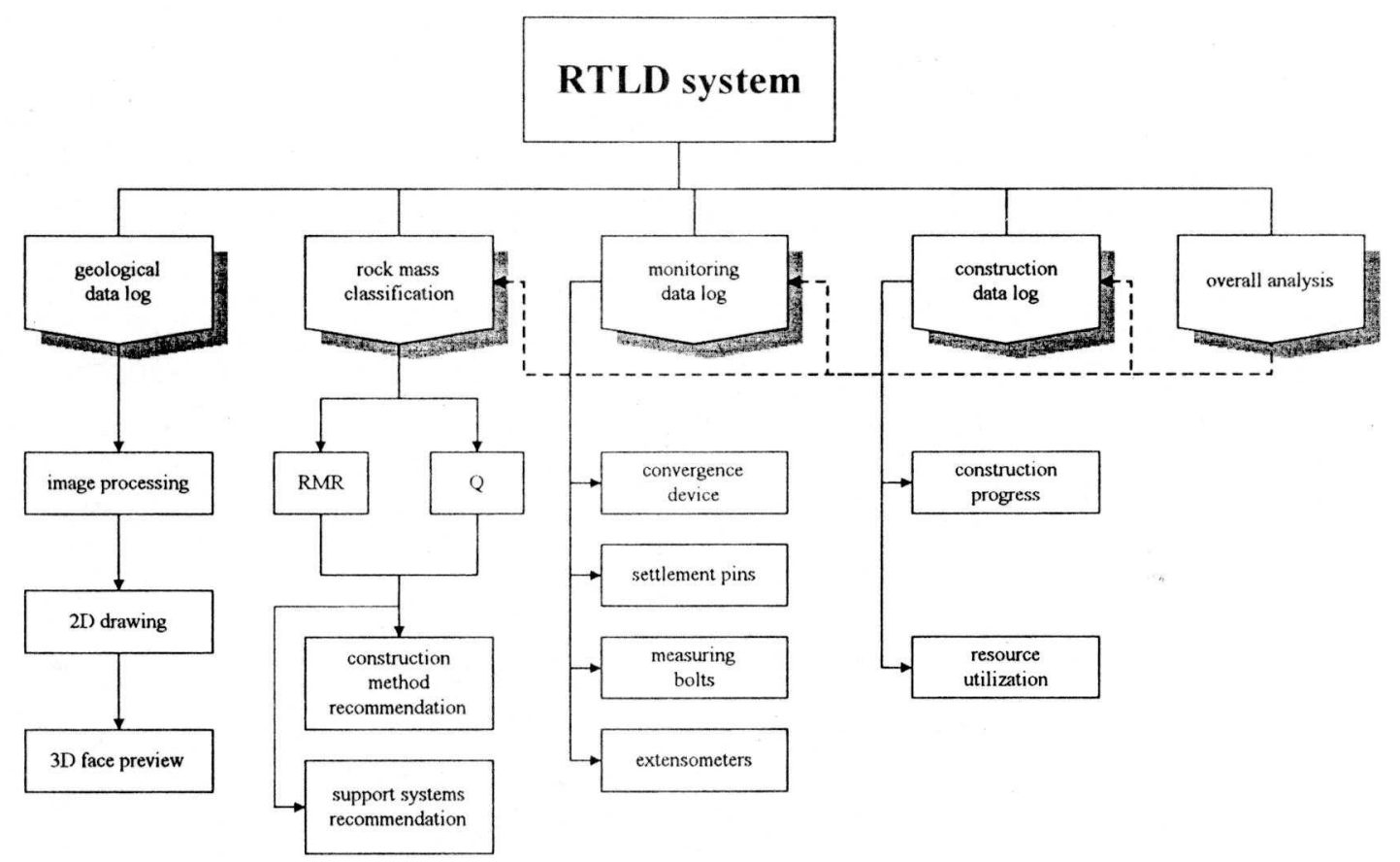

Figure 1 The Functional Structure of the RTLD

\section{DECISION MODULE SUBSYSTEM}

Rock mechanics is a young science. Recently, the rock tunnel design is using some analytical methods and computer systems for rock, such as FLAC, UDEC and FLAC-3D. However, due to the complex nature of rock masses, practical experiences and engineering judgments still constitute the main foundation on which the design and construction of the NATM tunnel are based. The engineering judgments are mainly based on expertise and statistical analysis of observational data. The functions of the decision module subsystem in the RTLD include both.

- Expertise - the studies from experts [Grimstad 1993, Bieniawski 1993, Sakurai 1993] are used to establish the kernel of the decision module. The construction methods, safety control systems, and geomechanical data calculation are some examples of the system functions, based upon experts' experiences.

- Statistical analysis of observational data - due to the uniqueness of each tunnel, the behaviors of the tunnel can be totally different. Practically, the constructors will modify the construction process and the support system, based on in situ observational data and their analysis. Typical analysis focuses on rock mass classification data, monitoring data, construction-related data, and their correlation 


\section{IMPLEMENTATION OF THE RTLD}

On the internal level, a major task is to translate the conceptual schema to a logical schema. In this stage, the Microsoft Visual Basic ${ }^{\mathrm{TM}}$ and the U-lead ImagePals ${ }^{\mathrm{TM}}$ (image processing system) are used to implement the system. The menubar and the dialog compose the main user interfaces (see Figure 2). The pen-based notebook computer is the main device to record in situ data. All the information about rock geology, rock mass classification, monitoring, and construction can be input separately or integratedly. The main functions of the system are data input, semi-automatic image processing, excavation face preview, construction method recommendation, safety warning system, data trend display, and correlation analysis. Each of the functions is briefly described as follows:

- Data input: data of parameters of rock mass classification (RMR and Q system), monitoring data, and construction-related data are input, basically using selection tables and auxiliary cross reference popup windows.

- Semi-automatic image processing: in order to overcome the disadvantage of manual drawing of geological conditions, such as faults and rock layers, a semi-automatic geological recording subsystem is provided. At first, a rock face image is shot by a digital camera. Secondly, the image is imported through RS-232 into the U-lead ImagePals. The image is adjusted to a standard size and then the geologist can straightforward draw the faults and rock layers on the screen. These data are stored in the geometrical format.

- Excavation face preview: the geometrical data of the existing consecutive excavation faces are analyzed, and then the declination and orientation angles of the succeeding faults and rock layers are shown graphically.

- construction method recommendation: based on the sum-up score of the RMR or the Q system, the construction methods (e.g., the depth of shotcrete, types of support, etc.) recommended by Bieniawski, Barton, or design consultants are displayed automatically.

- data trend display: historical data are retrieved individually or in group, and then and displayed on the trend sheets or the grid sheets.

- correlation analysis: in order to sufficiently support the in situ judgments, correlations among rock mass classification data, monitoring data and construction-related data are analyzed and shown graphically. The main types of correlation are type of support vs. rock type, quantity of dynamite vs. rock type, final rock movement vs. rock type, and construction progress vs. rock type, etc.

\section{CONCLUSION}

The quick proliferation of tunnel-related data indicates the need of a well-organized information system. The proposed object-oriented data model with the GUI and the image processing is an attempt to support effective data recording and utilization. There are several benefits to this approach. It is easy to record faults and rock layers through the image processing system. Using the GUI and the pen-based input, the site engineer can easily keep 
tunnel-related information. The correlation analysis among tunnel-related data provides indepth messages to assist site judgments.

\section{ACKNOWLEDGMENTS}

This information presented in this article is based on research sponsored by the Taiwan Area National Expressway Engineering Bureau, Ministry of Communications as well as Construction and Planning Administration, Ministry of Interior, R.O.C. This support is gratefully acknowledged. The writers also would like to express their gratitude to Chen CheeNan and Chen Yao-Chung for their guidance in the survey.

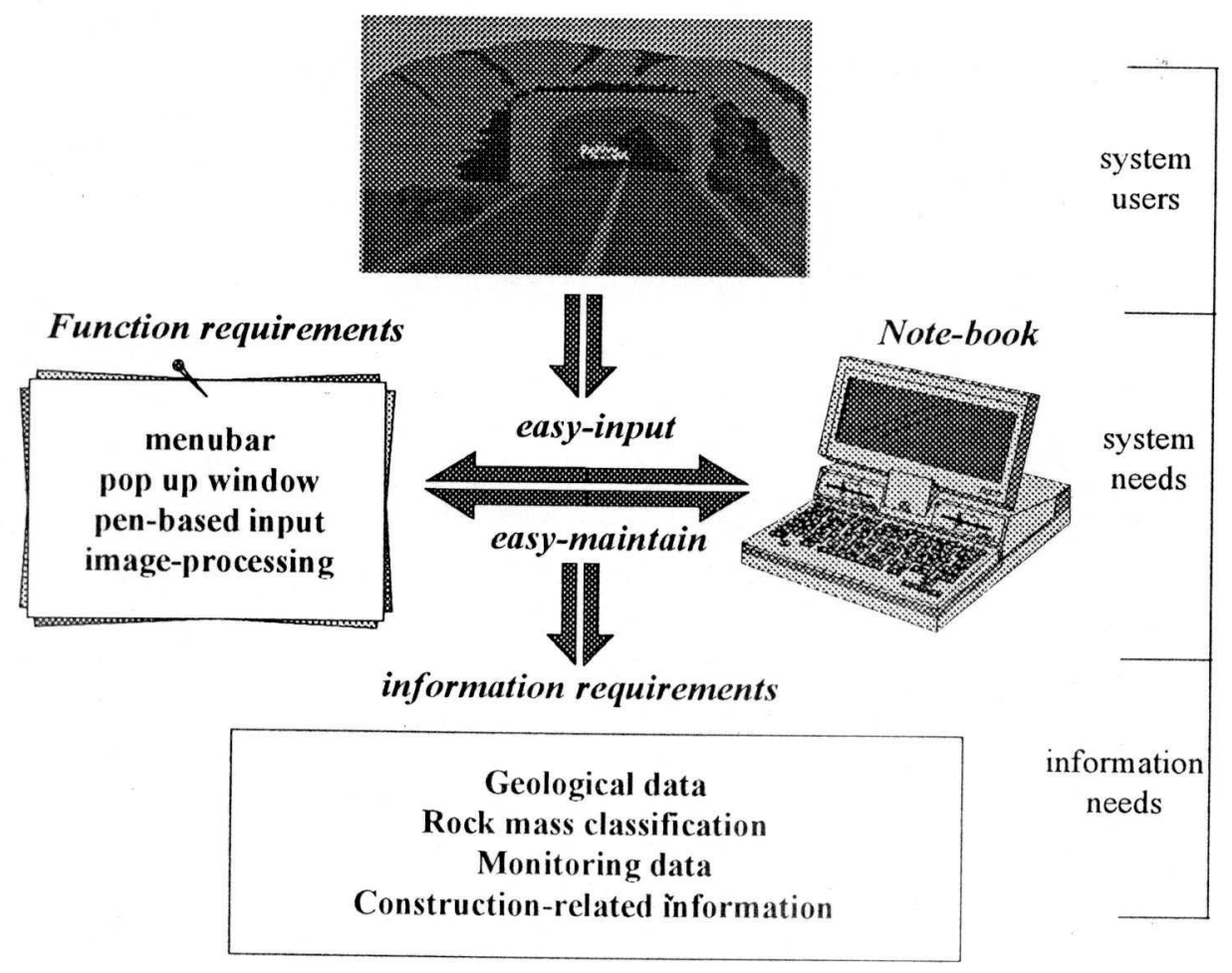

Figure 2 The Operation Environment of The RTLD

\section{REFERENCES}

[Elmasri 89] Elmasri, Ramez and Navathe, S. B., Fundamentals of Database System, Benjamin/Cummings, Redwood, California 1989. 
[Sprague 89] Sprague, Ralph H. Jr. and Watson, Hugh J., Decision Support System: Putting Theory into Practice, Prentice-Hall International, 1989.

[Booch 91] Booch, Grady, Object Oriented Design with Application, Benjamin/Cummings, 1991.

[Grimstad 93] Grimstad, E. and Barton, N., "Updating of the Q System for NMT", in Proceeding of International Symposium on Sprayed Concrete, edited by Reidar Kompen, etc., Norway, 1993.

[Bieniawski 93] Bieniawski, Z.T., "Classification of Rock Masses for Engineering: the RMR System and Future Trends", in Comprehensive Rock Engineering, edited by Hudson, John A., Volume 3, 1993.

[Sakurai 93] Sakurai S., "The Assessment of Tunnel Stability on the Basis of Field Measurements", in XVIII Convegno Nazionale Di Geotechnica, Rimini, Italy, 1993. 